\title{
Ischemia Procedure
}

National Cancer Institute

\section{Source}

National Cancer Institute. Ischemia Procedure. NCI Thesaurus. Code C131331.

A surgical procedure during which the blood supply to an organ or tissue is interrupted and then later reestablished. 